MRS Advances (C) 2017 Materials Research Society

DOI: 10.1557/adv.2017.150

\title{
Seed Layer Assisted Hydrothermal Deposition of Low-resistivity ZnO Thin Films
}

\author{
Eugene Chubenko $^{1}$, Vitaly Bondarenko ${ }^{1}$, Amir Ghobadi ${ }^{2}$, Gamze Ulusoy ${ }^{3}$, Kağan Topalli ${ }^{3}$, Ali \\ Kemal Okyay ${ }^{2,3}$ \\ ${ }^{1}$ Belarusian State University of Informatics and Radioelectronics, \\ Minsk, 220013, Belarus \\ ${ }^{2}$ Department of Electrical and Electronics Engineering, Bilkent University, \\ Bilkent, Ankara, TR 06800, Turkey \\ ${ }^{3}$ UNAM-National Nanotechnology Research Center and Institute of Materials Science and \\ Nanotechnology, Bilkent University, Bilkent, Ankara, TR 06800, Turkey
}

\begin{abstract}
In this work, we describe the combination of hydrothermal and atomic layer deposition (ALD) for growing low-resistivity $\mathrm{ZnO}$ polycrystalline continuous films. The effect of the thickness of ALD seed layers on the morphology of the hydrothermal $\mathrm{ZnO}$ films was studied. It was shown that $\mathrm{ZnO}$ films hydrothermally deposited on very thin seed layer consist of separate nanorods but in the case of $20 \mathrm{~nm}$ seed layer $\mathrm{ZnO}$ films transform to uniform continuous layers comprising of closely packed vertically aligned crystallites. Photoluminescence spectra were shown to exhibit broad band behavior in the visible range, corresponding to radiative recombination processes via oxygen defects of $\mathrm{ZnO}$ crystalline lattice, and narrow band in the UV region, associated with band-to-band recombination processes. It was shown that the resistivity of the obtained $\mathrm{ZnO}$ films is decreased gradually with the increase of $\mathrm{ZnO}$ films thickness and determined by the presence of crystal lattice defects in the seed layer.
\end{abstract}

\section{INTRODUCTION}

$\mathrm{ZnO}$ is a promising material for optoelectronics, photovoltaics and sensor applications [1, 2]. $\mathrm{ZnO}$ has unique combination of physical and chemical properties: wide direct band-gap, high exciton binding energy $[3,4]$ and transparency in optical and near IR-region $[1,5]$, prominent photocatalytic activity [6]. The key advantage of $\mathrm{ZnO}$ is that it can be fabricated by numerous techniques in the form of continuous films and nanostructures arrays even without lithography assistance [2, 3]. Molecular beam epitaxy, chemical vapor deposition, atomic layer deposition (ALD) and other vacuum based methods allow to deposit $\mathrm{ZnO}$ films with good crystalline quality. However, they become very expensive in the case of large substrates and have high operational temperature which is crucial for producing the integrated heterostructures [3]. Liquid phase electrochemical and chemical depositions are not so technologically demanding, but produce $\mathrm{ZnO}$ films with more structural defects and uncontrolled impurities $[2,7,8]$. Combination of vacuum based and liquid phase methods gives an opportunity to fabricate $\mathrm{ZnO}$ films with special structural and physical properties [2].

In this work, hydrothermal deposition as representative of liquid phase methods was applied to deposit thick $\mathrm{ZnO}$ continuous films on thin $\mathrm{ZnO}$ seed layers formed by ALD method on the $\mathrm{Si}$ and $\mathrm{SiO}_{2}$ substrates. It was supposed that seed layer could reduce the substrate influence on morphology of hydrothermal $\mathrm{ZnO}$ films, provides uniformity, good adhesion and better precipitation for growing hydrothermal $\mathrm{ZnO}$ crystals which is useful for practical application of obtained hydrothermal $\mathrm{ZnO}$ films. 


\section{EXPERIMENTAL}

Monocrystalline Si wafers of n-type and p-type conductivity with (100) crystallographic orientation were used as substrates. Thin layer of $\mathrm{SiO}_{2}$ of approximately $100 \mathrm{~nm}$ in thickness was formed on the surface of p-type $\mathrm{Si}$ wafers by thermal oxidation. No oxidation was used for the ntype $\mathrm{Si}$ wafers. Thin $\mathrm{ZnO}$ seed layers were formed by ALD method on the surface of substrates of both types. ALD of ZnO layers were carried out at $200{ }^{\circ} \mathrm{C}$ in a Savannah S100 ALD reactor. The thickness of seed layers was different and varied from minimal value - corresponding to 2 cycles of ALD process, to approximately $20 \mathrm{~nm}$. Hereinafter these layers will be referred as "thin" and "thick", correspondingly. Thick $\mathrm{ZnO}$ layers with thickness up to several microns were hydrothermally deposited on the surface of ALD ZnO seed layers. Hydrothermal $\mathrm{ZnO}$ deposition was carried out during 120 and $240 \mathrm{~min}$ from an aqueous $0.1 \mathrm{M} \mathrm{ZnNO}_{3}$ solution containing 0.1 $\mathrm{M}$ of hexamethylenetetramine (HMTA). $\mathrm{pH}$ at level of 5.2 (at $20^{\circ} \mathrm{C}$ ) was adjusted by $\mathrm{HNO}_{3} .50$ $\mathrm{ml}$ thermostated glass autoclave was used for $\mathrm{ZnO}$ hydrothermal deposition. The substrates were placed horizontally with work side down on a PTFE holder. Substrates were immersed into the solution at $65^{\circ} \mathrm{C}$ and then autoclave was heated to target temperature of $85^{\circ} \mathrm{C}$. After the process, completed substrates were rinsed in distilled water and dried in the air.

Hitachi-S4800 scanning electron microscope (SEM) was used to study the morphology and structure of the obtained $\mathrm{ZnO}$ films. XRA analysis was carried out with Bruker QUANTAX 200 EBSD analyzer. XPS spectra were obtained with Thermo Scientific K-alpha XPS spectrograph operating at $1 \mathrm{kV}$ of Argon ion beam energy level. For XRD analysis modified computerized DRON-3M X-ray diffractometer was used. Photoluminescence spectra were registered with spectroscopic complex based on Solar TII MS 7504i spectrograph equipped with CCD camera for signal registration. Photoluminescence was excited with $1 \mathrm{~kW}$ Xe lamp. Monochromatic lines from the broad lamp spectra were cut by double monochromator Solar TII DM 160. The resistivity of the obtained $\mathrm{ZnO}$ films was measured by $\mathrm{DC}$ four-probe method on the potentiogalvanostat Metrohm Autolab PGSTAT302N based setup. Probes were made of copper and arranged in in-line configuration. The distance between probes was $1 \mathrm{~mm}$.

Measurements were carried out only for samples formed on p-type $\mathrm{Si}$ with insulating $\mathrm{SiO}_{2}$ buffer layer. As the thickness of studied $\mathrm{ZnO}$ films was much smaller than the distance between the probes, in the calculation of resistivity it was considered that electrical field extends to the entire thickness of the $\mathrm{ZnO}$ film and lower boarder of film is in contact with infinite insulating layer. All optical and electrical measurements were performed at the room temperature.

\section{RESULTS AND DISCUSSION}

$\mathrm{ZnO}$ "thin" seed layer was not distinguishable on the cross-section SEM images of the substrates. The concentration of $\mathrm{Zn}$ atoms in the "thin" film is below 1 at.\% and could not be accurately determined because of low concentration and limitations of the method used. We believe that thickness of "thin" seed layer is no more than several angstroms. The thickness of "thick" seed layers measured on SEM images is approximately $16 \mathrm{~nm}$. According to the results of XRA analysis concentration of $\mathrm{Zn}$ atoms in the "thick" $\mathrm{ZnO}$ seed layer is 36 at.\% if $\mathrm{ZnO}$ is taken as 100 at.\%, i.e. the composition of $\mathrm{ZnO}$ seed layer is not stoichiometric.

It is shown that the morphology of $\mathrm{ZnO}$ films formed by hydrothermal deposition on the surface of seed $\mathrm{ZnO}$ layers depends on the seed layer thickness. SEM images of the $\mathrm{ZnO}$ film hydrothermally deposited during 120 min on the "thin" seed layer are shown on Fig. 1. ZnO film 
consists of individual $\mathrm{ZnO}$ crystals with prominent hexagonal shape typical for $\mathrm{ZnO}$ with wurtzite crystal lattice [3,4]. The crystals are not well oriented and chaotically dispersed across the surface of the wafers. The obtained $\mathrm{ZnO}$ crystals are of relatively large diameter up to $3 \mu \mathrm{m}$. Typical twining of $\mathrm{ZnO}$ crystals [9, 10] of the so-called "dumbbell" type is also visible on the top-view SEM images (Figs. 1 b, d). It was found that the structure and size of deposited crystals are the same for the substrates with and without $\mathrm{SiO}_{2}$ layer. The concentration of $\mathrm{ZnO}$ crystals on the substrate with $\mathrm{SiO}_{2}$ layer is lower. It means that "thin" seed layer helps in the nucleation and precipitation of hydrothermally formed $\mathrm{ZnO}$ crystals even on $\mathrm{SiO}_{2}$ surface. However, lack of crystal structure of seed layer of that type not allowed oriented growth of $\mathrm{ZnO}$ crystals.

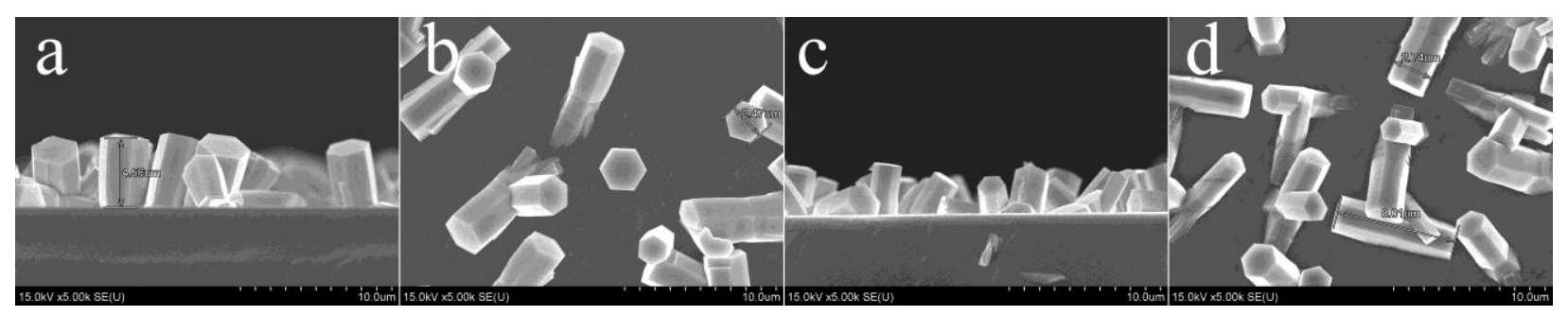

Figure 1. Cross-section and plain view SEM images of $\mathrm{ZnO}$ crystals hydrothermally deposited on the surface of monocrystalline Si wafer with "thin" seed layer with (a, b) and without (c, d) $\mathrm{SiO}_{2}$ buffer layer.

Seed ALD ZnO layer of $20 \mathrm{~nm}$ thickness is shown to have a strong effect on the structure of hydrothermal $\mathrm{ZnO}$ films. These $\mathrm{ZnO}$ films obtained on the $\mathrm{Si}$ wafers with "thick" seed layer consist of tightly packed $\mathrm{ZnO}$ crystallites and contain some pore-like gaps (Fig. 2). The thickness of $\mathrm{ZnO}$ film hydrothermally deposited during $120 \mathrm{~min}$ is approximately $1.5 \mu \mathrm{m}$. On the plain view SEM images, the slightly distorted hexagonal shape of the $\mathrm{ZnO}$ crystallites is visible which is characteristic for $\mathrm{ZnO}$ with wurzite type crystalline lattice [3, 4].

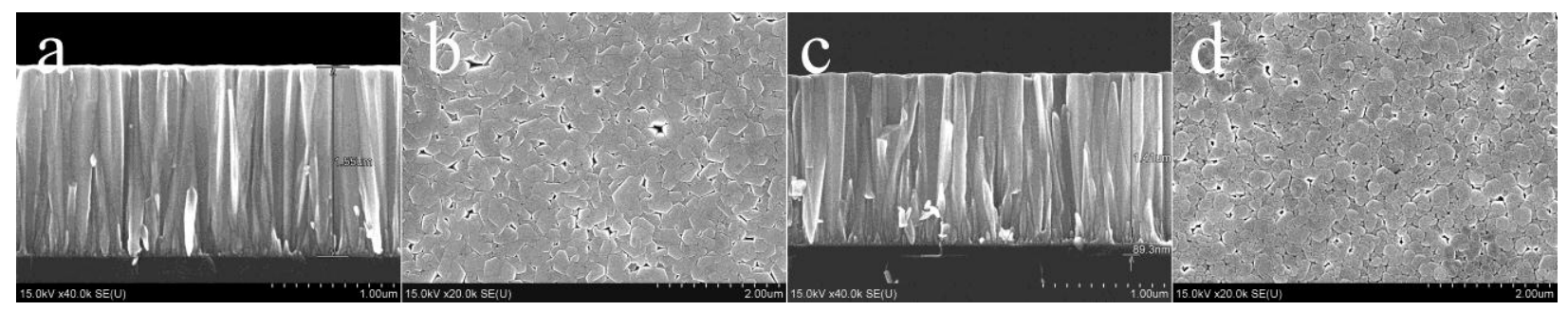

Figure 2. Cross-section and plain view SEM images of $\mathrm{ZnO}$ thin films hydrothermally deposited during 120 min on the surface of monocrystalline Si wafer with "thick" seed layer with (a, b) and without (c, d) $\mathrm{SiO}_{2}$ buffer layer.

$\mathrm{ZnO}$ thin films deposited on the "thick" seed layer contain approximately 50 at.\% of zinc and 50 at.\% of oxygen, i.e. they have stoichiometric composition. Excess of oxygen is not higher that $0.1-0.2$ at.\%. Hydrothermally deposited $\mathrm{ZnO}$ films usually have stoichiometric composition, determined by features of chemical reactions occurring during deposition [11]. According to XRD data (Fig. 3, a) independently of $\mathrm{Si}$ wafers used (with or without $\mathrm{SiO}_{2}$ layers) fabricated $\mathrm{ZnO}$ films are polycrystalline and consist of crystallites with hexagonal crystal lattice and have dominant crystallographic orientation (0002). It is important to note that XRD spectra of initial 
seed layer also demonstrate dominant (0002) crystallographic orientation (Fig. 3, b) and peak associated with (1011) phase. Despite the fact that during hydrothermal deposition in the presence of HMTA ZnO crystals grow in the direction [0002] perpendicular to wafer surface, the presence of phase (1011) and similar phases (1012) and (1013) in the seed layer and hydrothermally grown $\mathrm{ZnO}$ means that the latter inherit structural properties of seed layer.
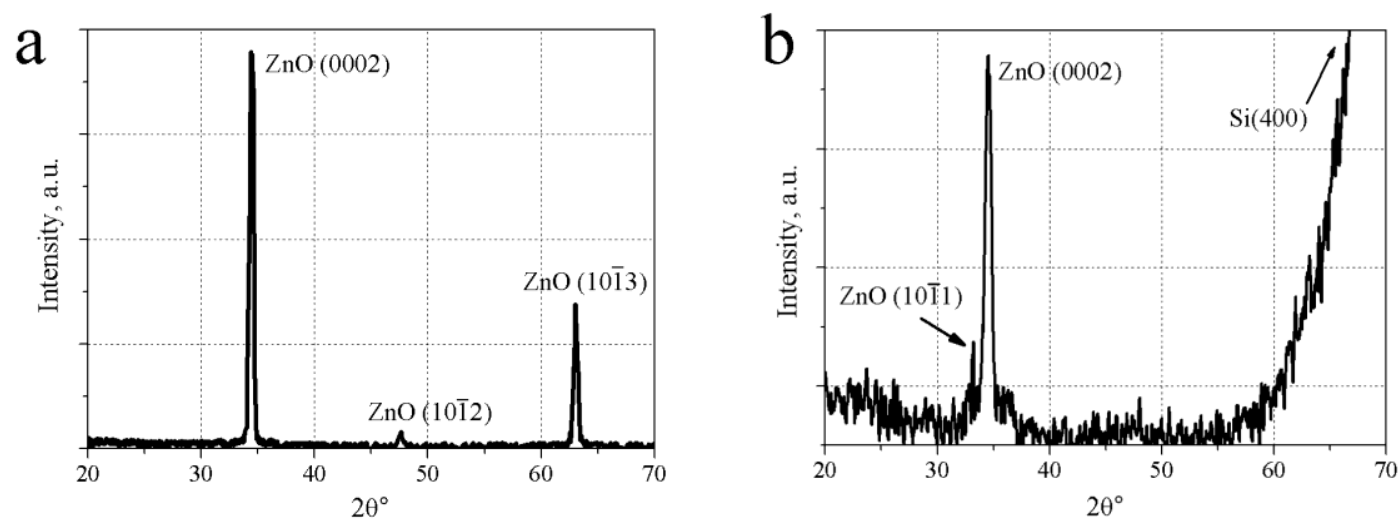

Figure 3. XRD spectra of $\mathrm{ZnO}$ thin film hydrothermally deposited during $120 \mathrm{~min}$ on $\mathrm{Si}$ wafer with "thick" seed layer (a) and $\mathrm{ZnO}$ "thick" seed layer itself (b). It should be noted that intensive dominant $\mathrm{Si}$ (400) peak can obscure (1013) ZnO peak.

XPS analysis revealed the presence of structural defects in the hydrothermal $\mathrm{ZnO}$ films (Fig. 4). XPS spectra of $\mathrm{ZnO} 1$ s oxygen band contain several components at 530, 531 and 532 $\mathrm{eV}$ corresponding to oxygen ions bounded to $\mathrm{Zn}$ atoms in $\mathrm{ZnO}$ crystal lattice (referred as $\mathrm{O}_{\mathrm{L}}$ on Fig. 4), oxygen ion in the region with oxygen vacancies in $\mathrm{ZnO}$ crystal lattice $\left(\mathrm{O}_{\mathrm{V}}\right)$ and chemisorbed oxygen $\left(\mathrm{O}_{\mathrm{C}}\right)$ [12]. The presence of $\mathrm{O}_{\mathrm{C}}$ band is associated with loosely bound oxygen on the surface of $\mathrm{ZnO}$ film and attributed to the presence of $\mathrm{OH}^{-}$groups adsorbed during hydrothermal $\mathrm{ZnO}$ deposition [11]. The intensity of $\mathrm{O}_{\mathrm{C}}$ band on XPS spectra increases with thickness of hydrothermal $\mathrm{ZnO}$ film and it means that the concentration of hydroxyl group adsorbed at the $\mathrm{ZnO}$ surface increases as well. In the same time, relative contribution of $\mathrm{O}_{\mathrm{V}}$ component in the intensity of oxygen $1 \mathrm{~s}$ band decreases.
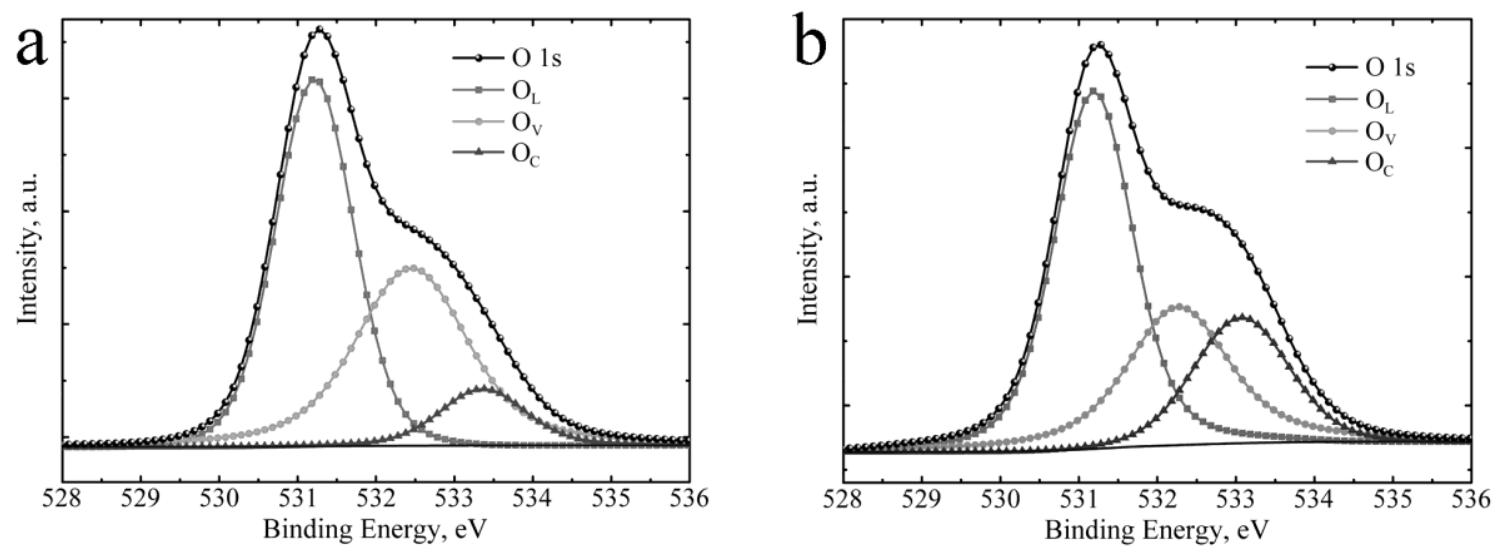

Figure 4. O 1s band on XPS spectra of ZnO films hydrothermally deposited on "thick" seed layer during $120 \mathrm{~min}$ (a) and $240 \mathrm{~min}(\mathrm{~b})$. 
The photoluminescence spectra presented on the Fig. 5 revealed the presence of oxygen related defects in the $\mathrm{ZnO}$ crystal lattice. The wide band with two maximums at 580 and $650 \mathrm{~nm}$ at the photoluminescence spectra corresponds to irradiative recombination via energy levels in the $\mathrm{ZnO}$ band gap associated with oxygen vacancies in $\mathrm{ZnO}$ crystal lattice and interstitial oxygen atoms [5, 13]. Narrow band with the maximum at $380 \mathrm{~nm}$ is also presented on the spectra. It corresponds to the band-to-band irradiative recombination process as that wavelength is equivalent to $3.34 \mathrm{eV}$ - the energy of $\mathrm{ZnO}$ band gap.

There is no significant difference in the intensity of photoluminescence bands of the $\mathrm{ZnO}$ films deposited during 120 and $240 \mathrm{~min}$. As seen from Fig. 5 the intensity of the defect related broad band in the visible range for the sample with longer deposition time increased on 10-12\%, while the intensity of band-to-band recombination band increased on 55-57\%. This can be explained by the fact that concentration of crystal structure defects in the surface layers of $\mathrm{ZnO}$ films deposited during longer time is lower and their crystallinity is overall better. This correlates with the results of XPS analysis of the obtained $\mathrm{ZnO}$ films. The similar results were observed for $\mathrm{ZnO}$ films deposited on $\mathrm{Si}$ and $\mathrm{SiO}_{2}$ substrates. It means that properties of hydrothermally deposited $\mathrm{ZnO}$ films in the first order determined by the parameters of seed layer and are not correlate with the nature of underlying substrate materials.

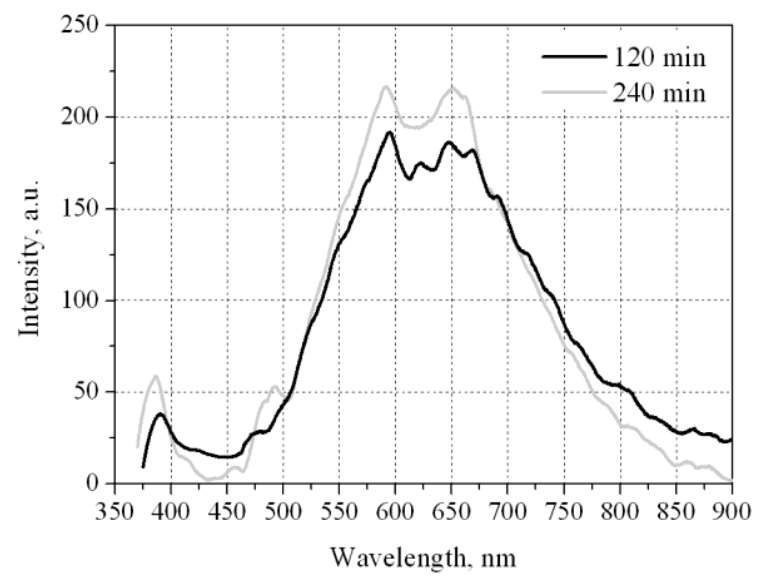

Figure 5. Photoluminescence spectra of $\mathrm{ZnO}$ thin films hydrothermally deposited on "thick" seed layer during 120 and $240 \mathrm{~min}$.

The resistivity of "thick" ZnO seed layer deposited by ALD was of $2 \cdot 10^{-5} \mathrm{Ohm} \cdot \mathrm{cm}$ as measured by four-probe method. However, the resistivity of double-layer structure consisting of “thick' seed layer and $\mathrm{ZnO}$ film hydrothermally deposited during 120 and 240 min was 0.7 and $1.7 \mathrm{Ohm} \cdot \mathrm{cm}$, respectively. The $\mathrm{ZnO}$ seed layers were undoped that is why the relatively low resistivity can be defined only by high concentration of intrinsic defects forming donor levels in the oxide semiconductor band gap contributing to the majority charge carries concentration. Hydrothermally deposited $\mathrm{ZnO}$ films contain less structural defects and hence have higher resistivity. We suppose that $\mathrm{ZnO}$ crystallites deposited by hydrothermal deposition inherit structural defects of ALD seed layer. However, the concentration of those defects gradually dropped with the increase of film thickness. It is confirmed by change of the ratio of intensities of photoluminescence bands in visible and UV region for samples with different thickness and the results of XPS investigations. In other words, $\mathrm{ZnO}$ layers located on greater distance from the substrate and seed layer have better crystallinity. 


\section{CONCLUSIONS}

The method of fabricating $\mathrm{ZnO}$ films by combination of ALD and hydrothermal deposition techniques is presented. It was shown that the morphology of hydrothermally deposited $\mathrm{ZnO}$ films depends on the thickness of ALD seed layer. Compact uniform $\mathrm{ZnO}$ films with the thickness of several microns could be formed only on seed layer of $20 \mathrm{~nm}$ thickness. Fabricated $\mathrm{ZnO}$ films are polycrystalline with dominant (0002) crystallographic orientation. It was found that the relatively low resistivity of the deposited $\mathrm{ZnO}$ films is defined by high concentration of intrinsic defects - primarily oxygen vacancies. Thick $\mathrm{ZnO}$ films deposited on the seed layer inherit structural defects of the seed layer however the concentration of those defects as well as electrical conductivity gradually decreased with the increase of $\mathrm{ZnO}$ film thickness. This also indirectly confirmed by the increase of the intensity of photoluminescence band with maximum at $380 \mathrm{~nm}$. Deposited $\mathrm{ZnO}$ films also demonstrate photoluminescence in the visible range associated with recombination via oxygen related crystal lattice defects energy levels in the $\mathrm{ZnO}$ band gap. The compact uniform $\mathrm{ZnO}$ films fabricated by combination of hydrothermal and ALD techniques can be used in optoelectronic and photovoltaic devices.

\section{ACKNOWLEDGMENTS}

The work has been funded as a part of the Belarus Government Research Program "Photonics, opto- and microelectronics", Grant 2.1.02, and "Physical materials science, novel materials and technologies", Grant 2.21.

\section{REFERENCES}

1. Ü. Özgür, D. Hofstetter and H. Morkoç, Proc. IEEE 98, 1255 (2010).

2. A. Kołodziejczak-Radzimska and T. Jesionowski, Materials 7, 2833 (2014).

3. Ü. Özgür, Ya. I. Alivov, C. Liu, A. Teke, M.A. Reshchikov, S. Doğan, V. Avrutin, S.-J. Cho and H. Morkoç, Appl. Phys. Rev. 98, 1 (2005).

4. T.C. Collins and R.J. Hauenstein, in Zinc oxide materials for electronic and optoelectronic device applications, edited by C.W. Litton, D.C. Reynolds and T.C. Collins (John Wiley and Sons Ltd., 2011), pp. 1-28.

5. A. Pimentel, E. Fortunato, A. Gonçalves, A. Marques, H. Águas, L. Pereira, I. Ferreira and R. Martins, Thin Solid Films 487, 212 (2005).

6. K.M. Lee, C.W. Lai, K.S. Ngai and J.C. Juan, Water Res. 88, 428 (2016).

7. D. Lincot, Thin Solid Films 487, 40 (2005).

8. M. Balucani, P. Nenzi, E. Chubenko, A. Klyshko and V. Bondarenko, J. Nanopart. Res. 13, 5985 (2011).

9. B.G. Wang, E.W. Shi and W.Z. Zhong, Cryst. Res. Technol. 33, 937 (1998).

10. Q. Yu, C. Yu, H. Yang, W. Fu, L. Chang, J. Xu, R. Wei, H. Li, H. Zhu, M. Li and G. Zou, Inorg. Chem. 46, 6204 (2007).

11. S. Baruah and J. Dutta, Sci. Technol. Adv. Mater. 10, 013001 (2009).

12. M. Chen, X. Wang, Y.H. Yu, Z.L. Pei, X.D. Bai, C. Sun, R.F. Huang and L.S. Wen, Appl. Surf. Sci. 158, 134 (2000).

13. W.C. Zhang, X.L. Wu, H.T. Chen, J. Zhu and G.S. Huang, J. Appl. Phys. 103, 093718 (2008). 